\title{
Mechanical characterization of the enamel microstructure treated with non alcoholic drinks
}

DOI: $10.46932 / \mathrm{sfjdv2n2-048}$

Received in: january 1st, 2020

Accepted in: March 30th, 2020

Lazo Gabriel E.

Doctor en Odontología.

Decano de la Facultad de Odontología Universidad Nacional de La Plata.

Calle 50 entre Av. 1 y calle 115. La Plata Bs. As. Argentina.

E-mail: gaedlazo@hotmail.com

\section{Abal Adrián A}

Doctor en Odontología.

Facultad de Odontología Universidad Nacional de La Plata.

Calle 50 entre Av. 1 y calle 115. La Plata Bs. As. Argentina.

E-mail: drpanacea2003@yahoo.com.ar

\section{Belloni Federico}

Odontólogo

Facultad de Odontología Universidad Nacional de La Plata.

Calle 50 entre Av. 1 y calle 115. La Plata Bs. As. Argentina.

E-mail: fedejunior1@yahoo.com

\section{Merlo Diego A \\ Odontólogo}

Facultad de Odontología Universidad Nacional de La Plata.

Calle 50 entre Av. 1 y calle 115. La Plata Bs. As. Argentina.

E-mail: dieguitomerlo@ hotmail.com

\section{Barceló Miguel A}

Odontólogo Facultad de Odontología Universidad Nacional de La Plata.

Calle 50 entre Av. 1 y calle 115. La Plata Bs. As. Argentina.

E-mail: andresbarcelood@gmail.com

\section{Barrasa Emanuel $\mathbf{H}$}

Odontólogo Facultad de Odontología Universidad Nacional de La Plata.

Calle 50 entre Av. 1 y calle 115. La Plata Bs. As. Argentina.

E-mail: emanuelbarrasaa@ hotmail.com

Pérez Patricia S.

Odontóloga Facultad de Odontología Universidad Nacional de La Plata.

Calle 50 entre Av. 1 y calle 115. La Plata Bs. As. Argentina.

E-mail: patogelptyg@gmail.com

\section{Tanevitch Andrea M.}

Doctora en Odontología. Mg. En Educación Odontológica. Facultad de Odontología Universidad Nacional de La Plata. 


\title{
Calle 50 entre Av. 1 y calle 115. La Plata Bs. As. Argentina.
}

E-mail: atanevitch@gmail.com

\begin{abstract}
In previous studies, it has been shown that the microstructure of prismatic dental enamel presents differences between the external and internal zone. Radial enamel is found in the outer third of enamel and has higher microhardness values than enamel with Hunter- Schreger Bands (HSB) that occupies the inner $2 / 3$. Our aim was to evaluate the mechanical behavior of radial enamel and HSB due the action of a non-alcoholic beverage in vitro. Longitudinal sections of dental crowns were embedded in polymer, worn and polished with sandpapers of decreasing granulation. The samples were immersed in a flavoured natural water for 12 minutes. Nanohardness tests (Triboindenter Hysitron) were performed on the radial and HSB enamel before and after the exposure to the drink. Hardness determinations " $\mathrm{H}$ ", reduced modulus "Er" and contact depth "hc" were obtained. The percentage of reduction of hardness was determined. The values found in healthy radial enamel were H: $5.48 \pm 0.23 \mathrm{GPa}$; Er: $86.97 \pm 8.11 \mathrm{GPa}$; hc: $149.73 \pm 4.25 \mathrm{~nm}$ and in HSB H: $4.24 \pm 0.43 \mathrm{GPa}$; Er: $75.24 \pm 7.09 \mathrm{GPa}$; hc: $176.36 \pm 11.29 \mathrm{~nm}$. After exposure to beverage, it was found in the radial enamel H: $2.22 \pm 0.31 \mathrm{GPa}$; Er: $58.73 \pm 10.79 \mathrm{GPa}$; hc: $270.29 \pm 21.22 \mathrm{~nm}$, and in HSB H: $1.54 \pm 0.42 \mathrm{GPa}$; Er: $48.11 \pm 6.54 \mathrm{GPa}$; hc: $350.10 \pm 63.33 \mathrm{~nm}$. After the drink action, the values of hardness of the radial enamel and HSB decreased and the trend observed in healthy enamel remained, where the highest values corresponded to the radial enamel. The percentage reduction of $\mathrm{H}$ in the radial enamel was $59.48 \%$ and in the HSB enamel it was $63.67 \%$. The contact depth increased by about $50 \%$. The decrease in hardness is related to the mineral loss produced by the acids contained in the drink. We conclude that the action of the non-alcoholic beverage produces a decrease in the mechanical properties in both the radial enamel and the HSB. The lower values in the reduced module Er indicate the formation of a superficial softened layer, the enamel with HSB being more vulnerable.
\end{abstract}

Key words: dental enamel, hardness, beverage, mineral loss.

\section{INTRODUCTION}

Nutrition plays a vital role in our lives not only contribute to the growth, development and conservation of the individual but influences the prevention and treatment of diseases by improving the quality of life and increasing longevity (de Abreu Rodrigues, 2020). Consumption of various commercial soft drinks is part of the dietary habits of the population, however, several studies have shown that intake of drinks with low $\mathrm{pH}$, such as fruit juices and soft drinks, produced varying degrees of erosion in the enamel of deciduous and permanent teeth (Cochrane, 2012; Lussi, 1993). The underlying acidity in beverages is the primary factor in dental erosion development because it determines the availability of hydrogen ions capable of interacting with the surface of the tooth. It also influences the type of acid and its calcium chelating properties, the time and temperature of exposure (von Fraunhofer, 2004). The way the drink is ingested is also associated with dental erosion: keep the beverage longer provokes mouth a more pronounced $\mathrm{pH}$ and drink with an increasing flow rate and with an outlet diameter fall downward may increase erosion depth (Cheng, 2009). 
In human dentition, enamel tissue has a defined organization of prisms according to the area concerned. Previous studies have shown that the free faces of permanent teeth, the prisms exhibit crosslinks $2 / 3$ of the thickness innermost giving rise to Hunter Schreger bands (HSB), while in the outer third, are arranged parallel each other, forming the radial enamel (Durso, 2018). This arrangement gives it a defined biomechanical behavior: the radial enamel is more effective against wear forces, while the decussating of the prism in the HSB provides resistance to tensional forces avoiding the propagation of fractures (Rensberger, 1997). Lynch (2010) argues that some conditions, including abfraction syndrome fractured tooth, seem to be passively supplied by distributions HSB, occurring in areas where packing densities HSB are relatively low, as the cervical regions of the tooth crown.

The adamantine tissue is characterized by the high mineral content that gives it resistance to multiple factors, but the teeth can suffer loss of substance not only due to mechanical forces but also due to the action of chemical agents, most frequently represented by acids from bacterial metabolism and the diet. Flavored waters have a natural water base that is associated with hydration and health, which is why its consumption has become widespread among people of all ages. Hence, the interest to study the effect of exposure of an orange flavored water on tooth enamel considering the different organization of the prisms during their path from the dentine-enamel junction towards the external surface.

The objective was to evaluate the mechanical behavior of the radial and HSB enamel to the action of a commercial orange flavored water in vitro.

\section{METODOLOGY}

For assays longitudinal sections of human dental crowns obtained with due informed consent patients were used. The sections were included in acrylic resin forming plugs that were worn and polished to obtain a flat, smooth and shiny surface buccolingual direction. Sandpapers were used to progressive water granulation (grain 1200, 1500, 2000 and 2000) and on final polishing was performed with high brightness and pulp driven rotary instruments cloth. The samples were washed with alcohol, then ultrasound for 5 minutes and dried. Microhardness tests were performed using a TRIBOINDENTER HYSITRON equipment with Berkovich indenter belonging to the Surface Laboratory of INTEMACONICET (Faculty of Engineering, National University of Mar del Plata). The loading function is a basic $4 \mu \mathrm{N}$ maximum load trapezoid, $2 \mathrm{sec}$ holding time, with loading and unloading rates of $800 \mu \mathrm{N} / \mathrm{sec}$. For each position/test area, a grid of $4 \times 4$ indentations $25 \mu \mathrm{m}$ apart was applied.

The results of $\mathrm{H}$ (hardness), Er (reduced modulus) and hc (depth of contact) were obtained by the Oliver-Phar methodology. Recordings were made in the outer zone of the thickness of the enamel (enamel radial) and internal (enamel BHS) before and after immersion in the beverage (Fig. 1). 
The percentage reduction of hardness after treatment was obtained by the formula:

$$
\Delta \mathrm{H}=\frac{\mathrm{Hi}-\mathrm{Hf}}{\mathrm{Hi}} \times 100
$$

Where Hi: is initial hardness; Hf: final hardness

Exposure to drink consisted of immersing the samples in $100 \mathrm{ml}$ of an orange flavored water commercially available, for 12 minutes, then removed and washed with water.

ANOVA test was used with Bonferroni multiple comparisons. The accepted error $\alpha$ was 0.05 .
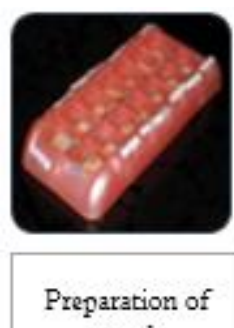
sample Inclusion in polymer
Fig. 1. Sequence of methodological steps
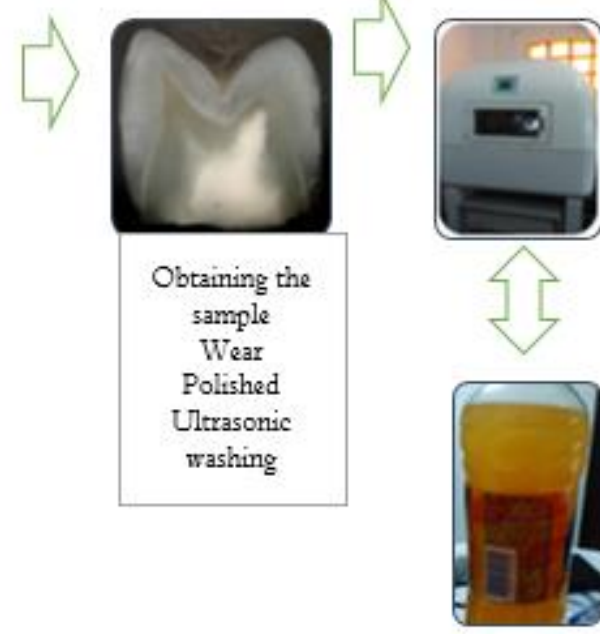

Obtaining the sample

Wear

Polished

Ultrasonic washing

\section{RESULTS}

Records determined differences between the hardness of the enamel and radial HSB both healthy tissue, and in the treated drinking. Healthy radial enamel presented higher hardness values than HSB. This trend was remained after the action of the drink. The values of $\mathrm{H}$ (hardness), Er (low modulus) and hc (depth of contact) of the healthy samples and treated as detailed in Table I. It was found significant difference $(\mathrm{p}<0,05)$ in hardness values of sound enamel and treated both radial enamel as in HSB (Fig. 2).

Table I. Mean values and deviation of Hardness (H), Modulus of elasticity (Er) and depth of contact (hc) of healthy enamel and treated with the drink.

\begin{tabular}{lllll} 
& & \multicolumn{1}{c}{ H $(\mathbf{G P a})$} & Er $(\mathbf{G P a})$ & \multicolumn{1}{c}{ Hc $(\mathbf{n m})$} \\
\hline HEALTHY & Radial & $5,48 \pm 0,23^{\text {ac }}$ & $86,97 \pm 8,11$ & $149,73 \pm 4,25$ \\
\cline { 2 - 5 } ENAMEL & HSB & $4,24 \pm 0,43^{\text {ad }}$ & $75,24 \pm 7,09$ & $176,36 \pm 11,29$ \\
\hline TREATED & Radial & $2,22 \pm 0,31^{\text {bc }}$ & $58,73 \pm 10,79$ & $270,29 \pm 21,22$ \\
ENAMEL & HSB & $1,54 \pm 0,42^{\text {bd }}$ & $48,11 \pm 6,54$ & $350,10 \pm 63,33$ \\
\hline
\end{tabular}

Equal letters indicate that the difference is significant (ANOVA, $p<0,05$ ) 
Fig. 2. Mean values of hardness $H$ (deviation and error) of healthy and treated enamel, radial and HSB. The radial healthy enamel presented higher mean values than the bands, both in the healthy enamel and after the action of the drink.

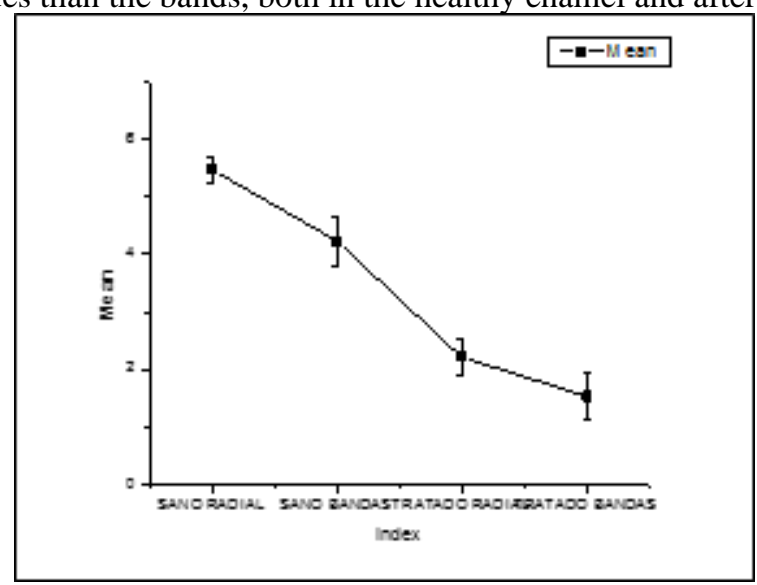

After the action of the drink, the hardness values of radial enamel and HSB decreased and the trend observed in healthy enamel was remained, where the highest values corresponded to radial enamel.

The comparative graph (Fig. 3) shows a decrease in $\mathrm{H}$ and Er values in both radial enamel and HSB. The percentage of $\mathrm{H}$ reduction in radial enamel was $59.48 \%$ and in HSB enamel, it was $63.67 \%$. Instead, the depth of contact increased by $50 \%$.

Fig. 3. Comparison of the nanohardness records of the treated / healthy enamel considering the external area (BHS enamel). The treated group (Muestras tratadas) presented lower hardness and elastic modulus values than healthy enamel (Muestras sanas). The contact depth increased after immersion in the beverage. The hardness was higher in radial enamel than in HSB enamel.

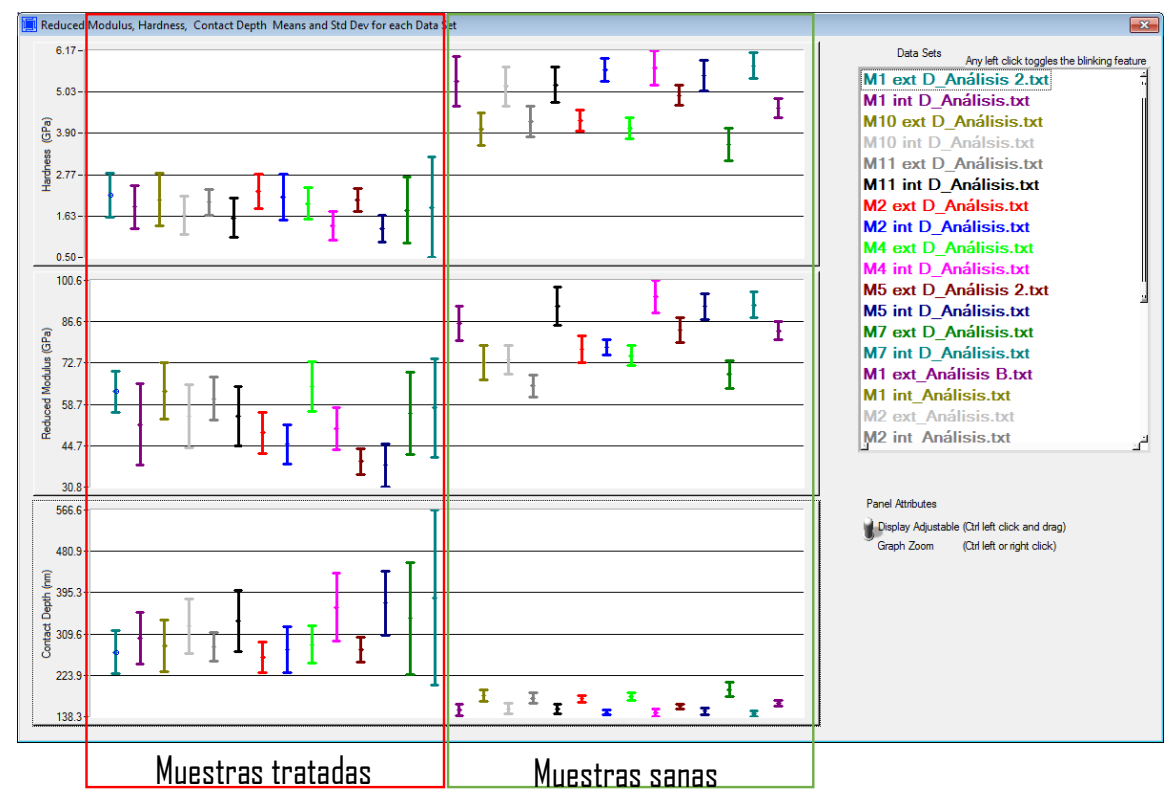




\section{DISCUSSION}

In this in vitro experiment, we explored the effect produced by flavoured water on the microhardness of tooth enamel samples, taking into account different zones in the enamel because of prisms positions.

The action of the flavoured water produced a loss of minerals from the adamantine tissue that was evidenced in the reduction of the reduced modulus values and an increase in the indentation depth. Previous studies demonstrated different resistance to wear in healthy radial enamel and with HSB (Durso et al, 2018). The most important factor in the abrasion resistance of enamel is the direction of the prism axis relative to the occlusal surface. Enamel prisms whose orientation is perpendicular to the masticatory surface (as in radial enamel), offer great resistance to abrasion (Boyde y Fortelius, 1986). In accordance with the above, our study verified a lower resistance to wear of healthy enamel with HSB compared to radial enamel. After immersion in flavoured water, the hardness values decreased being the lowest value for enamel with HSB. Enamel hardness is related to various factors such as the degree of mineralization, orientation and anisotropy of the crystallites, and surface porosity. Most of the pores between the crystallites of healthy enamel are subnanometric in size but after the action of acids, they increase because of the loss of ions due to demineralization, causing a decrease in surface hardness. According to Lynch (2010), certain aspects of the densities and distributions of HSB packing would facilitate the increase in porosity after the action of acids, a condition that is beneficial in the restorative clinical techniques of enamel adhesion through acid etching, where the producing a rough or uneven enamel surface. Inside a prism, crystals have different directions from their initial deposit at the enamel-dentin junction (EDJ).Those perpendicular to the dentin are arranged parallel to each other, while those that run at an angle to the LAD diverge or converge on their way from the dentin to the outside, producing abrupt or continuous orientation changes. (Wilmers, 2020). It has been suggested that water and proteins accumulate in the spaces caused by marked discontinuities in the orientation of the crystallites, and it has been found that crystallites arrive or intercalate in this space frequently. At the periphery of the prism, the crystals are oriented at acute angles with their neighbours, so the content of organic material is higher. These crystallites are preferably etched with an acid treatment, which results in the distinctive appearance of the prism sheaths in micrographs. These findings indicate that the prism sheaths are protein-rich regions, although they are unlikely to constitute a continuous layer of organic material. (Wilmers, 2020).

Commercial beverages contain various additives that are ingredients intentionally added for modifying the physical, chemical, biological or sensory characteristics of a food. These can be antioxidants, thickeners, colorants, preservatives, etc. The acidulant content in non-alcoholic beverages causes a pH value well below the critical pH of hydroxyapatite, which is 5,5 (Nuñez 2010). The orange 
flavored water used in this experiment has additives with acidifying power such as E-330 (citric acid) and EDTA or ethylene-diamine-tetra-acetic acid. A descending the $\mathrm{pH}$ of the liquid medium surrounding the glass tooth enamel demineralization occurring calcium is released. The combination of citric acid and EDTA produces a chelating effect on calcium, losing availability to recover the remineralization phenomenon

It is important to promote nutritional habits from an early age, not only for a correct and nutritious diet, but also to promote better development It is important to consume healthy and nutritious foods such as fruits and vegetables daily and drink water when thirsty, avoiding its replacement with other fluids to promote healthy habits (de Abreu Rodrigues, 2020).

\section{CONCLUSION}

The action of flavored natural water produces a decrease in mechanical properties in both radial and banded enamel. The lowest hardness value was recorded on internal enamel where the Hunter Schreger bands are located. The interlinking of the prisms and the arrangement of the crystals would favor an increase in porosity due to the action of the acid contained in the drink, causing the reduction of microhardness and the formation of a softened surface layer, resulting in the enamel with Hunter Schreger Bands being more vulnerable. We conclude that the acid components contained in flavored water produces mechanical alterations compatible with erosion phenomena of dental enamel.

\section{ACKNOWLEDGMENT}

We would like to thanks Ing. Bernardo Daga (INTEMA-CONICET. UNMdelP) for his technical advises and Od. Lucas De Vita (FOLP-UNLP) for his help in the translation of this article. 


\section{REFERENCES}

Boyde A, Fortelius M. (1986) Development, structure and function of rhinoceros enamel. Zool J Linn Soc (87): $181-214$

Cheng, R., Yang, H., Shao, M. Y., Hu, T., \& Zhou, X. D. (2009). Dental erosion and severe tooth decay related to soft drinks: a case report and literature review. Journal of Zhejiang University. Science. B, 10(5), 395-399. https://doi.org/10.1631/jzus.B0820245

Cochrane NJ, Yuan Y, Walker GD, Shen P, Chang CH, Reynolds C, Reynolds EC. (2012) Erosive potential of sports beverages. Australian Dental Journal. (57): p. 359-364

de Abreu Rodrigues Fabiano (2020) Child nutrition process and habits of a food doctrine for a lifetime South Florida Journal of Development, Miami, oct./dec., v.1, n.4, p.211-217,

Durso G, Abal, A, Pérez P, Tanevitch A, Lemos Barboza, A. (2017) Composición y acidez de bebidas comerciales sin alcohol Revista de la Facultad de Odontología Publicación Informativa y Científica $\mathrm{p}$. 65-68. http://sedici.unlp.edu.ar/handle/10915/77580

Durso, G., Tanevitch, A., Abal, A., Llompart, G., Pérez, P., \& Felipe, P. (2018). Estudio de la micrestructura del esmalte dental humano en relación con la microdureza y la composición química. Revista Ciencias Morfológicas, 19(2), 1-9. Recuperado a partir de https://revistas.unlp.edu.ar/Morfol/article/view/3824

Lynch, C. D., O'Sullivan, V. R., Dockery, P., McGillycuddy, C. T., \& Sloan, A. J. (2010). Hunter-Schreger Band patterns in human tooth enamel. Journal of anatomy, 217(2), 106-115. Recuperado a partir de https://doi.org/10.1111/j.1469-7580.2010.01255.x

Núñez DP, García Bacall L. (2010) Biochemistry of dental caries. Rev Haban Cienc Méd. (On line). Abr. -jun. 2010; 9(2). http://scielo.sld.cu/scielo.php?script=sci_arttext\&pid=S1729-519X2010000200004

Rensberger, J. (1997) Mechanicals adaptation in enamel. En Tooth enamel microstructure, de W Koenigswald y P Sander, editado por W Koenigswald y P Sander, Rotterdam: Balkema p. 237-257.

von Fraunhofer J. Anthony, Roger Matthew M.(2004) Dissolution of dental enamel in soft drinks General Dentistry July-August pp.308-12 PMID: 15366295

Wilmers Jana, Bargmann Swantje (2020) Nature's design solutions in dental enamel: Uniting high strength and extreme damage resistance. Acta Biomaterialia, Vol. 107, p. 1-24. https://doi.org/10.1016/j.actbio.2020.02.019 